\title{
Predicting intention to use voluntary HIV counseling and testing services among health professionals in Jimma, Ethiopia, using the theory of planned behavior
}

\author{
This article was published in the following Dove Press journal: \\ Journal of Multidisciplinary Healthcare \\ 11 October 2013 \\ Number of times this article has been viewed
}

\section{Fira Abamecha' \\ Ameyu Godesso ${ }^{2}$ \\ Eshetu Girma ${ }^{3}$}

'Department of Nursing, Mizan-Tepi University, Mizan, ${ }^{2}$ Department of Sociology, Jimma University, Jimma, ${ }^{3}$ Department of Health Education and Behavioral Sciences, Jimma University, Jimma, Ethiopia
Correspondence: Fira Abamecha Department of Nursing, Mizan-Tepi University, P.O. Box 260, Mizan, Ethiopia $\mathrm{Tel}+25$ I9 I70I 92। I

Email firamecha@gmail.com
Background: To endorse involvement in voluntary HIV counseling and testing (VCT), it is essential to recognize factors that influence people in deciding whether to access VCT services and their underlying route factors. Theory of planned behavior (TPB) constitutes a proficient framework for predicting behaviors and intentions.

Objective: The aim of the study reported here was to assess the predicting ability of TPB in determining the intended use of VCT services among health professionals in Jimma, southwest Ethiopia.

Methods: This was an institution-based cross-sectional quantitative study of a sample of 336 health professionals in 12 selected districts of Jimma, southwest Ethiopia between February 5 to March 28, 2012. Data were collected using structured questionnaire self-administered by the study participants. A hierarchal multivariable linear regression model was used to predict the role of TPB constructs that can influence the intention to use VCT services.

Results: The constructs of TPB explained the variability in intention to use VCT by $27 \%$ ( $R^{2}$ adjusted $=0.27$ ). The standardized regression coefficients showed that the strongest predictor of intention to use VCT was subjective norms $(\beta=0.32, P<0.0005)$ followed by attitude $(\beta=0.21, P<0.002)$. Perceived behavioral control was not a significant predictor of intention to use VCT among the study group $(P=0.12)$.

Conclusion: The study revealed the possibility of describing the intention to use VCT among health professionals using TPB, with perceived social pressure being the leading predictor. In light of this, health intervention programs should be designed to develop health professionals' ability to resist norms that oppose the use of VCT and to change community-held norms against VCT use, provided they help individuals develop a positive attitude toward the services.

Keywords: HIV/AIDS, VCT, health professionals, intention, TPB

\section{Introduction}

To endorse involvement in voluntary HIV counseling and testing (VCT), it is essential to recognize factors that influence people in deciding whether to access VCT services and their underlying route factors. The theory of planned behavior (TPB) constitutes a proficient framework for predicting behaviors and intentions. ${ }^{1}$ It is a continuation of theory of reasoned action (TRA), which assumes people are rational beings who make wise use of the available information before performing a behavior.

However, TRA does not account for behaviors that are not under volitional control; as a result, Ajzen added perceived behavioral control (PBC), on the same 
level as attitude and subjective norms, as a predictor of intention and named the new theory, "theory of planned behavior."1

Studies have applied theoretical models ${ }^{3,4}$ in an effort to identify factors associated with the utilization of VCT services, while others have tested the applicability of the TPB, focusing on sexual behaviors such as intention to use a condom, ${ }^{5,6}$ intention to refuse sexual debut, ${ }^{7}$ and intended use of contraception ${ }^{8,9}$ in Africa.

In a Tanzanian study, PBC and attitude were the primary predictors of the intention to use VCT services, while subjective norms were less predictive. ${ }^{8}$ However, a study conducted in Ethiopia ${ }^{10}$ and a study in Uganda ${ }^{11}$ showed that subjective norms were more important predictors than attitude and PBC. Finally, another Ethiopian study showed that the strongest predictor of reporting intention was PBC. ${ }^{12}$

Focusing on health professionals from southwest Ethiopia, the aim of the study reported here was to assess the applicability of the TPB in predicting intended use of VCT services in this group.

\section{Materials and methods}

\section{Study design and settings}

This was an institution-based cross-sectional quantitative study conducted in the Jimma Zone, Ethiopia, from February 5 to March 28, 2012. Jimma is located in the Oromia Region of Ethiopia, $357 \mathrm{~km}$ southwest of Addis Ababa. The Jimma Zone is subdivided into 18 districts with a total estimated population of 2,770,329 according to the 2007 Central Statistical Agency census report.

\section{Study participants}

Health professionals included were at least diploma holders. Private health institutions were excluded to avoid double counting, since government health workers may be involved in private institutions and the number and services of these are minimal. Participants who were ill and unable to respond were excluded.

\section{Sampling}

Of the 18 districts in the zone, 12 were included in this study using simple random sampling technique. All 369 selected health professionals from the 12 selected districts were included in the study. Health professionals working (ie, employed) in government-owned health settings (both health centers and health offices) in all selected districts of the zone were included.

\section{Data collection}

Quantitative data were collected using a structured questionnaire adapted and modified from a previous study and sample questionnaire outlined by Fishbein and Ajzen. ${ }^{1,12}$ The questionnaire was translated into the local languages, Afan Oromo and Amharic, and then back translated into English by language experts. The questionnaire, in both local languages, was self-administered by study participants and the data were collected. In addition to the cognitive variables, the questionnaire covered sociodemographic information and information on history of HIV counseling and testing. (See "Measurement tools" in the "Supplementary materials" section.)

\section{Measurements}

Intention to access VCT services was measured using four items. Responses ranged from "Not likely at all" (1) to "Very likely" (5).

Direct attitude toward the use of VCT services was measured using four items on bipolar differential scales of seven points each.

Direct subjective VCT norms were measured using four items, with respondents asked to indicate their level of agreement on a scale from "Strongly disagree" to "Strongly agree." Relatively low and high composite scores indicated negative social pressure (pressure against the behavior - ie, VCT utilization) and positive social pressure (pressure in favor of the behavior [VCT utilization]), respectively.

Direct measure of PBC was measured using four items on bipolar differential scales of seven points. High composite scores showed strong perceived ability or less difficulty in using VCT services within the specified period. The mean scores were used in the regression analysis for all components of the theory.

The past VCT service use component considered whether an individual's past VCT experience of HCWs at least once in their lifetime. One item was used to ask respondents whether they had been tested for HIV in the past by indicating "Yes" or "No" as appropriate.

\section{Statistical analysis}

Data were checked for completeness, edited, coded, and carefully entered by the principal investigator for analysis using SPSS software (v 16.0; IBM Corporation, Armonk, NY, USA). Descriptive statistical measures such as the means and standard deviations were undertaken. A hierarchical multivariable linear regression analysis was performed to predict intention to use VCT services. Standardized $\beta$ coefficients and adjusted $R^{2}$ values were used to interpret the effects and variability in 
the dependent variable, respectively. A $P$-value $<5 \%$ was considered to indicate significant association.

\section{Quality control of data}

Pretesting on $5 \%$ of a sample drawn from unselected districts was conducted prior to data collection to assess the cultural sensitivity and clarity of the items in the questionnaire. As already mentioned, the structured questionnaire in English was translated into two local languages, Afan Oromo and Amharic, and back translated into English by another person to check its validity. Clarification was provided to participants prior to distribution of the paper.

Further, confirmatory principal component analysis was performed to validate and check whether items were loaded to their respective constructs. It showed that the four items measuring each of the direct measures of TPB components and intention were loaded on their respective factors, creating four concepts after varimax rotation. Here, Eigenvalues $>1$ were assumed to retain the underlying factors (Table 1).

\section{Results}

A total of 336 (63\% male) health care professionals participated in the study. The response rate was $91 \%$. The respondents' age ranged from 20 to 58 years (mean $=27.5$, standard deviation $=2.7)$. Concerning marital status, $171(\sim 51 \%)$ were married, 149 (44\%) were single, and four (1.2\%) were divorced/separated (Table 2).

A total of $121(36 \%)$ individuals in the study had been tested for HIV by a VCT counselor and received post-test counseling, while $106(31 \%)$ tested their blood by themselves and 109 (33\%) had never been tested. The majority (215 [64\%]) of the study group had not obtained VCT services from counselors.

The most frequently stated reasons for receiving the test results (post-test counseling) were: fear of infection (65 [19\%]), fear of risk (52 [15.3\%]), and wishing to get married (39 [11.6\%]).
In terms of profession, nurses and environmental health professionals were the most and least likely, respectively, to obtain VCT, with $\sim 31 \%$ of nurses and $\sim 1.4 \%$ of environmental health professionals indicating that they had received $\mathrm{VCT}$.

Table 3 shows that the study group had favorable attitudes toward using VCT services, positively perceived social pressure in relation to VCT services, felt a modest level of perceived control of their behavior in using VCT services, and strong intentions to use these services.

\section{Prediction of intentions}

Hierarchical regression analysis was used to predict the amount of variance accounted for in the intention to use VCT services from a set of independent variables. Independent variables were entered (in steps) into the equation per the TPB assumptions.

Then, the independent variables were evaluated "in line with" / "against" the variability in the dependent variable, after controlling for the sociodemographic determinants and past history of VCT use.

Accordingly, the sociodemographic variables and past VCT experience were entered using the "enter method." In the first block, an $11 \%\left(R^{2}\right.$ change $=0.11, F$ change $=3.9$, $P<0.0005)$ variability in intention to use VCT services was shown. Following this, attitude was entered into the second block and a change in intention of $16 \%\left(R^{2}\right.$ change $=0.16$, $F$ change $=54.01, P<0.0005)$ was shown. The component subjective norms was entered in the third block, which brought a change in intention of $10 \%\left(R^{2}\right.$ change $=0.10, F$ change $=36.24, P<0.0005)$. Finally, $\mathrm{PBC}$ was entered in the last block and showed an insignificant change in the intention of $1 \%\left(R^{2}\right.$ change $=0.01, F$ change $\left.=3.53, P<0.061\right)$.

The TPB alone explained $27 \%$ of the overall variability in the intention to use VCT services $\left(R^{2}\right.$ adjusted $\left.=0.27\right)$ and the final model that included the components of TPB and sociodemographic variables explained intention to use VCT services by $34.2 \%\left(R^{2}\right.$ adjusted $\left.=0.342\right)$.

Table I Principal component analysis for direct measures of theory of planned behavior after varimax rotation with loading factors $>0.40$

\begin{tabular}{|c|c|c|c|c|c|}
\hline $\begin{array}{l}\text { Serial } \\
\text { number }\end{array}$ & Component & Number of items & $\begin{array}{l}\% \text { variance explained } \\
\text { after rotation }\end{array}$ & $\begin{array}{l}\text { Factor loading } \\
\text { change }\end{array}$ & Cronbach's alpha \\
\hline I & PBC & 4 & 19.94 & $0.78-0.87$ & 0.91 \\
\hline 2 & A & 4 & 19.65 & $0.73-0.89$ & 0.91 \\
\hline 3 & INT & 4 & $19.6 \mid$ & $0.77-0.86$ & 0.82 \\
\hline 4 & $\mathrm{SN}$ & 4 & 16.31 & $0.68-0.80$ & 0.89 \\
\hline 5 & Total & 16 & 75.51 & - & - \\
\hline
\end{tabular}

Abbreviations: A, attitude; INT, intention; PBC, perceived behavioral control; SN, subjective norms. 
Table 2 Sociodemographic characteristics of the study sample of health professionals from Jimma, Ethiopia $(\mathrm{N}=336)$

\begin{tabular}{|c|c|c|}
\hline Characteristic & Frequency & $\%$ \\
\hline \multicolumn{3}{|l|}{ Age, years $(n=336)$} \\
\hline $21-30$ & 275 & 80.9 \\
\hline $31-40$ & 50 & 14.7 \\
\hline $4 I-50$ & 11 & 3.5 \\
\hline \multicolumn{3}{|l|}{$\operatorname{Sex}(n=336)$} \\
\hline Male & 215 & 63.7 \\
\hline Female & 121 & 36.3 \\
\hline \multicolumn{3}{|l|}{ Religion $(n=33 \mathrm{I})$} \\
\hline Muslim & 120 & 35.3 \\
\hline Orthodox & 106 & 31.2 \\
\hline Protestant & 89 & 26.2 \\
\hline Other* & 16 & 4.7 \\
\hline \multicolumn{3}{|l|}{ Ethnicity $(n=336)$} \\
\hline Oromo & 236 & 69.4 \\
\hline Amhara & 43 & 12.6 \\
\hline Other** & 57 & 18 \\
\hline \multicolumn{3}{|l|}{ Marital status $(n=3 \mid 4)$} \\
\hline Not married & 149 & 43.3 \\
\hline Married & 171 & 50.3 \\
\hline Divorced/Separated & 4 & 1.2 \\
\hline \multicolumn{3}{|l|}{ Education $(n=329)$} \\
\hline Diploma & 158 & 46.5 \\
\hline Bachelor of science degree & 168 & 49.4 \\
\hline Master's degree & 3 & 0.9 \\
\hline \multicolumn{3}{|l|}{ Profession $(n=283)$} \\
\hline Nursing & 113 & 33.2 \\
\hline Public health officer & 45 & 13.2 \\
\hline Medical laboratory technician & 35 & 10.3 \\
\hline Pharmacy & 40 & 11.8 \\
\hline Midwifery & 28 & 8.2 \\
\hline Environmental health & 17 & 5 \\
\hline Other*** & 3 & 1.5 \\
\hline
\end{tabular}

Notes: *Catholic, Wakefata; **Tigre, Guraghae, Kafa, Wolyita, Dawro, Yem; ***Master of Public Health, Doctor of Dental Medicine.

The regression coefficients, shown in Table 4, indicate that subjective norms are the strongest predictor of intention to use VCT services $(\beta=0.32, P<0.0005)$ followed by attitude $(\beta=0.21, P<0.002)$. This means that a unit-positive change in the individual's perception about key persons

Table 3 Descriptive statistics for components of theory of planned behavior and intention for health professionals from Jimma Zone, Ethiopia $(\mathrm{N}=336)$

\begin{tabular}{llllll}
\hline Component & $\mathbf{N}$ & $\begin{array}{l}\text { Number } \\
\text { of items }\end{array}$ & $\begin{array}{l}\text { Scale } \\
\text { range }\end{array}$ & $\begin{array}{l}\text { Scale } \\
\text { mean (SD) }\end{array}$ & $\begin{array}{l}\text { Item } \\
\text { mean }\end{array}$ \\
\hline $\begin{array}{l}\text { Subjective } \\
\text { norms }\end{array}$ & 336 & 4 & $4-20$ & $14.45(3.37)$ & $3.6 \mathrm{I}$ \\
Intention & 336 & 4 & $4-20$ & $14.55(3.82)$ & 3.64 \\
PBC & 336 & 4 & $4-28$ & $19.40(6.14)$ & 4.85 \\
Attitude & 336 & 4 & $4-28$ & $21.26(5.19)$ & 5.32 \\
\hline
\end{tabular}

Note: The sum of each mean column does not total 336 due to missing cases. Abbreviations: PBC, perceived behavioral control; SD, standard deviation. thinking that their use of VCT services is a normative action, will change the individual's intention to use VCT services by 0.32 provided that the other conditions are unvaried. In other words, individuals who perceive that their significant others will approve of their using VCT services will have a $32 \%$ higher behavioral intention to use VCT services than their counterparts.

At the same time, a unit-positive change in attitude toward the advantage associated with the use of VCT services will change the individual's intention to use VCT services by $21 \%$ if all the other factors are kept constant.

\section{Discussion}

Among the aims of the present study, one was identifying the sociodemographic characteristics associated with likelihood of intention to use VCT services. However, the results of our study revealed no significant sociodemographic predictor, and this finding is comparable to an Ethiopian study ${ }^{8}$ among medical students and a Nigerian study ${ }^{13}$ among high school teachers.

With regard to sex, it is conventional that the sex differences in seeking VCT are mainly due to, among others, cultural, social, and biological factors such as male dominance and vulnerability to social risks like rape, especially in developing countries, that make females vulnerable to HIV infection. In this study, level of education and profession may have affected such sociocultural factors, which may be why we found a less than expected, insignificant, difference between males and females in terms of their intention to use VCT services. This insignificant difference may reflect that the social status of female health care professionals is different to that of other females in the general population.

In addition, nearly all health care professionals had equal and easy access to VCT facilities, as all of the settings were health centers of the same standards and the respondents working in these settings had enough knowledge to make use of VCT services.

Previous studies have used the TRA and TPB to predict the intention to perform a certain behavior among populations other than health care professionals. In addition, Fishbein and Ajzen, the authors of the theory, identified that the intention to perform a behavior is a function of attitude, subjective norms, and $\mathrm{PBC}$, and that this varies according to the behavior, the population under study, and the context. ${ }^{1}$

The study conducted to predict intention to use condoms among Tanzanian high school students using TPB showed 
Table 4 Hierarchical regression analysis model summary of components of theory of planned behavior predicting the intended use of voluntary HIV counseling and testing services among health professionals from Jimma Zone, Ethiopia

\begin{tabular}{lllllll}
\hline Model & $\begin{array}{l}\text { Component in } \\
\text { the model }\end{array}$ & $\boldsymbol{R}$ square & $\begin{array}{l}\boldsymbol{R} \text { square } \\
\text { adjusted }\end{array}$ & $\begin{array}{l}\boldsymbol{R} \text { square } \\
\text { change }\end{array}$ & $\boldsymbol{F}$ change & Sigma $\boldsymbol{F}$ change \\
\hline I & SD variables & 0.110 & 0.082 & 0.11 & 3.91 & 0.000 \\
2 & A & 0.268 & 0.242 & 0.16 & 54.01 & 0.000 \\
3 & A + SN & 0.360 & 0.335 & 0.10 & 36.24 & 0.061 \\
4 & A + SN + PBC & 0.369 & 0.342 & 0.01 & 3.53 & 0.001 \\
\hline
\end{tabular}

Abbreviations: A, attitude; PBC, perceived behavioral control; SD, sociodemographic; SN, subjective norms.

that the theory explained $42 \%$ of variance in students' intention to use condoms. ${ }^{6}$ Another study conducted on Tanzanian teachers also reported that $30 \%$ of variance in intention was explained by TPB. ${ }^{7}$ Moreover, a study conducted among female adolescents in Ethiopia showed that the theory could explain $27 \%$ of variance in their intention to use contraceptives. ${ }^{10}$ Similarly, in the study reported here, the components of TPB explained $27 \%$ of variance in intention to use VCT services, which is thus nearly in agreement with previous studies conducted in Ethiopia and Africa.

In the regression analysis, attitude added the largest proportion of variability to intention, followed by subjective norms. Finally, PBC showed insignificant changes to intention. Findings from a Tanzanian study among teachers showed that PBC added a larger proportion of variance than attitude and subjective norms. ${ }^{7}$ Similarly, an Ethiopian study among high school teachers revealed that attitude and subjective norms account for the largest proportion of variability in intention to use VCT services followed by PBC, which brought significant changes. ${ }^{8}$

The findings of that Ethiopian study are in agreement with the present study except that PBC was not significant in the present study. However, possible reasons for this discrepancy, according to the TPB, could be difference in behavior, target population, and circumstances in which the behavior would occur. ${ }^{1,2}$ The population in this study comprised health professionals, who may not worry about their capability of having VCT because they have knowledge of and skill in issues related to HIV/AIDS, including VCT services, unlike the general public.

The nonsignificant association between intention to seek VCT services and PBC should not be disregarded because it might be due to respondents' control belief, whereby the health care professionals may not be honest in putting themselves in a position where they are incapable of undertaking the services or, in short, there may be a possibility of their introducing social desirability bias. Further, there was a perception that people access VCT services if they are suspected of HIV because they may observe routine report data from VCT service centers, which often have a large number of people attending who are HIV positive.

The standardized regression coefficient results in this study indicate that intention to use VCT services was primarily due to subjective norms and attitude, while PBC was an insignificant predictor. This study revealed similar results to those of Ethiopian and Ugandan studies that showed that subjective norms were a more important predictor. ${ }^{11,14}$ However, other studies showed that PBC was the leading predictor of intention, followed by attitude and subjective norms. ${ }^{9}{ }^{12}$ In the present study, subjective norms was a more important predictor than the other components of TPB, which indicates that significant others have a great role to play in an individual's intention to use VCT services. The reason for this could be difference in behavior, target population, and the circumstances in which the behavior is occurring, ${ }^{1,2}$ as already mentioned.

Table 5 Standardized and unstandardized values of regression coefficients, beta, in the regression analysis of theory of planned behavior to predict the intended use of voluntary HIV counseling and testing services among health professionals from Jimma Zone, Ethiopia

\begin{tabular}{llllll}
\hline Serial number & Component & Unstandardized $\boldsymbol{\beta}$ & Standardized $\boldsymbol{\beta}$ & $\mathbf{P}$-value & $\mathbf{9 5 \%} \mathbf{C l}$ \\
\hline $\mathrm{I}$ & SD variables & - & - & - & - \\
2 & A & 0.15 & 0.21 & 0.002 & $0.06,0.25$ \\
3 & SN & 0.37 & 0.32 & 0.000 I & $0.23,0.50$ \\
4 & PBC & 0.08 & 0.12 & 0.061 & $-0.004,0.16$ \\
\hline Abbreviations: A, attitude; Cl, confidence interval; PBC, perceived behavioral control; SD, sociodemographic; SN, subjective norms.
\end{tabular}

Abbreviations: A, attitude; $\mathrm{Cl}$, confidence interval; PBC, perceived behavioral control; SD, sociodemographic; SN, subjective norms. 


\section{Conclusion}

In the context of this study, intention to use VCT services is a function of attitude and subjective norms, with subjective norms, or perceived social pressure, being the leading predictor.

PBC had no influence in determining intention to use VCT services among the study group. Further, health professionals were influenced by psychosocial factors in their intention to use VCT services like the general public, regardless of their level of education and profession. Sociodemographic factors had no role in intention to use VCT services.

It is recommended, therefore, that health interventions programs be designed to develop individuals' ability to resist norms that oppose the use of VCT services and to change community-held norms against VCT service use, provided they help individuals develop a positive attitude toward the services.

\section{Authors' contributions}

All authors contributed equally in planning and organizing the study, analyzing the data, developing the manuscript, reviewing and approving the final manuscript for publication.

\section{Disclosure}

The authors declare no conflicts of interest in this work.

\section{References}

1. Fishbein M, Ajzen I. Theory-based behavior change interventions: comments on Hobbis and Sutton. J Health Psychol. 2005;10(1):27-31.

2. Glanz K, Rimer BK, Viswanath K, editors. Health Behavior and Health Education: Theory, Research, and Practice. 4th ed. San Francisco, CA: Jossey-Bass; 2008.

3. Meadows J, Catalan J, Gazzard B. "I plan to have the HIV test" - predictors of testing intention in women attending a London antenatal clinic. J Health Psychol. 1993;5(2):141-148.
4. de Paoli MM, Manongi R, Klepp KI. Factors influencing acceptability of voluntary counselling and HIV-testing among pregnant women in Northern Tanzania. AIDS Care. 2004;16(4)411-425.

5. Lugoe W, Rise J. Predicting intended condom use among Tanzanian students using the theory of planned behaviour. J Health Psychol. 1999;4(4):497-506.

6. Bosompra K. Determinants of condom use intentions of university students in Ghana: an application of the theory of reasoned action. Soc Sci Med. 2001;52(7):1057-1069.

7. Kakoko DC, Astrøm AN, Lugoe WL, Lie GT. Predicting intended use of voluntary HIV counselling and testing services among Tanzanian teachers using the theory of planned behaviour. Soc Sci Med. 2006;63(4):991-999.

8. Shemsedin O, Jemal H. Applicability of the theory of planned behavior in predicting intended use of voluntary HIV counseling and testing services among teachers of Harari Region, Ethiopia. Ethiopian Journal of Health Development. 2010;24(2):96-102.

9. Molla M, Astrøm AN, Berhane Y. Applicability of the theory of planned behavior to intended and self-reported condom use in a rural Ethiopian population. AIDS Care. 2007;19(3):425-431.

10. Fekadu Z, Kraft P. Predicting intended contraception in a sample of Ethiopian female adolescents: the validity of the theory of planned behavior. Psychology and Health. 2000;16(2):207-222.

11. Pikard JL. HIV voluntary counselling and testing among Kenyan male youth aged 13-15 years: the theory of planned behaviour applied [master's thesis]. Kingston, ON: Queen's University; 2009. Available at: qspace.library.queensu.ca/bitstream/1974/5350/1/ Pikard_Jennifer_L_200911_MSc.pdf. Accessed August 20, 2013.

12. Daniyam CA, Agaba PA, Agaba E. Acceptability of voluntary counselling and testing among medical students in Jos, Nigeria. J Infect Dev Ctries. 2010;4(6):357-361.

13. Sherr L, Lopman B, Kakowa M, et al. Voluntary counselling and testing: uptake, impact on sexual behaviour, and HIV incidence in a rural Zimbabwean cohort. AIDS. 2007;21(7):851-860.

14. Bwambale FM, Ssali SN, Byaruhanga S, Kalyango JN, Karamagi CA. Voluntary HIV counselling and testing among men in rural western Uganda: implications for HIV prevention. BMC Public Health. 2008;8:263. 


\section{Supplementary material \\ Measurement tools}

Part I: sociodemographic characteristics

\begin{tabular}{|c|c|c|c|}
\hline Serial number & Question & Categories & \\
\hline \multirow[t]{2}{*}{ I } & Sex & Male & I \\
\hline & & Female & 2 \\
\hline 2 & What is your current age in complete years? & & \\
\hline \multirow[t]{5}{*}{3} & What is your religion? & Muslim & I \\
\hline & & Orthodox & 2 \\
\hline & & Protestant & 3 \\
\hline & & Catholic & 4 \\
\hline & & Other; please specify: & \\
\hline \multirow[t]{4}{*}{4} & What is your ethnic group? & Oromo & I \\
\hline & & Amhara & 2 \\
\hline & & Tigre & 3 \\
\hline & & Other; please specify: & \\
\hline 5 & What is your profession? & & \\
\hline \multirow[t]{5}{*}{6} & Please indicate the last qualification you obtained & Diploma & I \\
\hline & & BSc degree & 2 \\
\hline & & Master's degree & 3 \\
\hline & & $\mathrm{PhD}$ & 4 \\
\hline & & Other; please specify: & _ \\
\hline \multirow[t]{4}{*}{7} & Please indicate your marital status & Single & 1 \\
\hline & & Married & 2 \\
\hline & & Divorced & 3 \\
\hline & & Widowed/Separated & 4 \\
\hline 8 & What is your total monthly salary in Birr? & 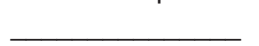 & \\
\hline 9 & Year of recruitment & & \\
\hline
\end{tabular}

\section{Part II: direct TPB (theory of planned behavior) measurements}

The following questions ask about your intentions, attitudes, social pressures, and your perceived difficulty of using VCT (voluntary HIV counseling and testing) services in the next 3 months. Encircle the number that best represents your choice according to your degree of agreement with the statement.

1. How likely is it that you will need HIV counseling and testing services in the next 3 months?
1. Very unlikely
2. Unlikely
3. Neutral
4. Likely
5. Very likely

2. In the coming 3 months, how likely is it that you will be tested for HIV?
1. Very unlikely
2. Unlikely
3. Neutral
4. Likely
5. Very likely

3. In the next 3 months, how likely is it that you will look for and request VCT services?
1. Very unlikely
2. Unlikely
3. Neutral
4. Likely
5. Very likely

4. In the next 3 months, how likely is it that you will use VCT services?
1. Very unlikely
2. Unlikely
3. Neutral
4. Likely
5. Very likely

5. Your receipt of VCT services in the 3 months will be (please give a separate answer for each question):

$\begin{array}{lllllllll}\text { 5.1. Not beneficial } & 1 & 2 & 3 & 4 & 5 & 6 & 7 & \text { Beneficial } \\ \text { 5.2. Unpleasant } & 1 & 2 & 3 & 4 & 5 & 6 & 7 & \text { Pleasant } \\ \text { 5.3. Useless } & 1 & 2 & 3 & 4 & 5 & 6 & 7 & \text { Useful } \\ \text { 5.4. Bad } & 1 & 2 & 3 & 4 & 5 & 6 & 7 & \text { Good }\end{array}$

6. Most people who are important to you will approve of your using VCT services in the next 3 months.
1. Strongly disagree
2. Disagree
3. Neutral
4. Agree
5. Strongly agree

7. Most people like you want to use VCT services in the next 3 months.
1. Very unlikely
2. Unlikely
3. Neutral
4. Likely
5. Very likely 
8. It is expected of you that you will use VCT services in the next 3 months.
1. Strongly disagree
2. Disagree
3. Neutral
4. Agree
5. Strongly agree

9. Most people who are important to you think that you should use VCT services in the next 3 months.
1. Strongly disagree
2. Disagree
3. Neutral
4. Agree
5. Strongly agree

10. For you to use VCT services in the next 3 months is (please give an answer for each question):

$\begin{array}{lllllllll}\text { 10.1. Difficult } & 1 & 2 & 3 & 4 & 5 & 6 & 7 & \text { Easy } \\ \text { 10.2. Not under control } & 1 & 2 & 3 & 4 & 5 & 6 & 7 & \text { Under control } \\ \text { 10.3. Unconditional } & 1 & 2 & 3 & 4 & 5 & 6 & 7 & \text { Conditional } \\ \text { 10.4. Sudden } & 1 & 2 & 3 & 4 & 5 & 6 & 7 & \text { Planned }\end{array}$

\section{Part III: VCT status}

1. Have you ever been tested for HIV/AIDS before?
1. Yes
2. No

2. If yes, when was the last time you used VCT services?

1. Three months ago

2. Six months ago

3. Twelve months ago

4. Other; please specify:

3. How many times did you use VCT services?
1. Once
2. Twice
3. Three or more times

4. Have you received post-test counseling and the test result?

1. Yes

2. No

5. If yes, why did you choose to receive the result? (More than one answer is possible.)

1. Fear that I could be infected

2. Fear that I was professionally at risk

3. I want/wanted to donate blood/organs

4. I had/have an unfaithful partner

5. I want/wanted to get married

6. Where did you use VCT services? (More than one answer is possible.)

1. Government health institution

2. Private health institution

3. Friendly health service institution

7. Who provided the VCT services to you?

1. VCT counselor

2. Self

3. Other; please specify:

\section{Operational definitions and measurements Intention of having VCT}

This referred to the individual's plan to use HIV counseling and testing in the near future (next 3 months). Generalized intention was measured using four items $(\alpha=0.89)$. Responses ranged from "not likely at all" (1) to "very likely" (5). A high total score/mean score indicated a high intention to use VCT and were used in the analysis. 


\section{Attitude toward the use of VCT}

This meant an individual's predisposition to respond in a favorable or unfavorable manner toward the use of VCT. This was measured using four items on bipolar differential scales $(\alpha=0.92)$. A high total score indicated a highly favorable attitude.

\section{Direct subjective VCT norms}

This was an individual's perception that significant others, in general, think that the individual uses VCT services as a normative action. Four items $(\alpha=0.82)$ were used to measure this component in which respondents had to indicate their level of agreement with a statement on a scale from "Strongly disagree" to "Strongly agree." Relatively low and high composite scores indicated negative social pressure (pressure against the behavior - ie, VCT utilization) and positive social pressure (pressure in favor of the behavior [VCT utilization]), respectively.

\section{Direct measure of perceived behavioral control}

This indicated an individual's confidence about using VCT services in the next 3 months, if they desired to. This was measured using four items on bipolar differential scales $(\alpha=0.91)$. High composite scores showed strong perceived ability or less difficulty in using VCT services within the specified period.

\section{Past VCT service use}

This component considered past VCT experience of health care professionals at least once in their lifetime. One item was used to ask respondents whether they had been tested for HIV in the past by indicating "Yes" or "No" as appropriate.

\section{Publish your work in this journal}

The Journal of Multidisciplinary Healthcare is an international, peerreviewed open-access journal that aims to represent and publish research in healthcare areas delivered by practitioners of different disciplines. This includes studies and reviews conducted by multidisciplinary teams as well as research which evaluates the results or conduct of such teams or health- care processes in general. The journal covers a wide range of areas and welcomes submission from practitioners at all levels, from all over the world. The manuscript management system is completely online and includes a very quick and fair peer-review system. Visit http://www.dovepress. com/testimonials.php to read real quotes from published authors. 